\title{
Inventarisasi Kupu-Kupu di Desa Serdang Menang, Kecamatan Sirah Pulau Padang, Kabupaten Ogan Komering Ilir
}

\author{
Ari Sugiarto \\ Email: sugiartoari13@gmail.com
}

\begin{abstract}
Abstrak
Desa Serdang Menang merupakan salah satu desa yang ada di Kecamatan Sirah Pulau Padang, Kabupaten Ogan komring Ilir memiliki beragam ekosistem, mulai dari ekosistem sungai, persawahan, perkebunan, dan permukiman yang tentunya juga memiliki keragaman spesies yang ada didalamnya. Keragaman tipe ekosistem juga mempengaruhi keberadaan kupu-kupu. Perlu dilakukan inventarisasi kupu-kupu di Desa Serdang Menang, Kecamatan Sirah Pulau Padang, Kabupaten Ogan komering Ilir untuk mengetahui spesies kupu-kupu apa saja yang ada. Penelitian ini dilaksanakan di Desa Serdang Menang, Kecamatan Sirah Pulau Padang, Kabupaten Ogan Komering Ilir pada Oktober 2018. Pengambilan sampel kupu-kupu dengan menggunakan metode jelajah. Pengambilan sampel dilakukan menggunakan insecting net. Indentifikai spesies kupu-kupu dilakukan dengan mencocokan sampel dengan foto kupukupu yang sudah diidentifikasi jenisnya. Hasil penelitian menunjukkan terdapat 10 spesies kupu-kupu dari 6 Famili yaitu Carterocephalus palaemon dari Famili Hesperiidae, Euchrysops cnejus dari Famili Lycaenidae, Danaus melanippus, Maniola jurtina, dan Neptis hylas dari Famili Nymphalidae, Papilio lowi dari Famili Papilionidae, Appias libythea, Catopsilia pyranthe, dan Eurema hecabe dari Famili Pieridae, dan Abisara echerius dari Famili Riodinidae. Kupu-kupu yang ditemukan paling banyak terdapat pada perbatasan ekosistem perkebunan dan persawahan.
\end{abstract}

Kata Kunci: Kupu-Kupu, Ekosistem, Desa Serdang Menang

\section{Pendahuluan}

Kecamatan Sirah Pulau Padang merupakan salah satu kecamatan yang ada di Kabupaten Ogan Komering Ilir. Menurut Katalog BPS OKI (2017), luas Kecamatan Sirah pulau Padang yaitu $149,08 \mathrm{~km}^{2}$ yang terdiri dari 20 Desa. Salah satu Desa yang ada di Kecamatan Sirah Pulau Padang yaitu Desa Serdang Menang.

Desa Serdang Menang memiliki tipe ekosistem beragam mulai dari ekosistem sungai, persawahan, perkebunan, dan permukiman. Keragaman tipe ekosistem ini tentunya juga diikuti dengan keragaman spesies yang ada didalamnya. Keragaman tipe ekosistem juga mempengaruhi keberadaan kupu-kupu. Hal ini didukung oleh penelitian Lestari et al. (2015), distribusi kupu-kupu pada tipe hutan berbeda-beda. Penelitian dari Rahayuningsih et al. (2012) juga menunjukkan pada tipe ekosistem hutan sekunder, permukiman, daerah aliran sungai, dan persawahan terdapat perbedaan jumlah spesies dan jumlah individu kupu-kupu.

Belum tersedianya data mengenai spesies kupu-kupu yang ada di Desa Serdang Menang, maka perlu dilakukan inventarisasi kupu-kupu di Desa Serdang Menang, Kecamatan Sirah Pulau Padang, Kabupaten Ogan komering Ilir untuk mengetahui spesies kupu-kupu apa saja yang ada.

\section{Metode Penelitian}

Penelitian ini dilaksanakan di Desa Serdang Menang, Kecamatan Sirah Pulau Padang, Kabupaten Ogan Komering Ilir pada Oktober 2018. Pengambilan sampel kupu-kupu mengikuti metode penelitian yang dilakukan oleh Dalem \& Joni (2017) dengan menggunakan metode jelajah. 
Pengambilan sampel dilakukan menggunakan insecting net. Sampel yang didapat dimasukkan dalam aplop kertas minyak agar sayap kupu-kupu tidak rusak. Dilakukan juga pengukuran intensitas cahaya, kelembaban, dan suhu udara pada lokasi sampling. Indentifikai spesies kupukupu dilakukan dengan mencocokan sampel dengan foto kupu-kupu yang sudah diidentifikasi jenisnya

\section{Hasil dan Pembahasan}

Berdasarkan penelitian yang telah dilakukan di Desa Serdang Menang, Kecamatan Sirah Pulau Padang, Kabupaten Ogan Komering Ilir didapatkan spesies kupu-kupu yaitu:

Tabel 1. Spesies kupu-kupu di Desa Serdang Menang, Kecamatan Sirah Pulau Padang, Kabupaten Ogan Komering Ilir

\begin{tabular}{lll}
\hline Famili & Genus & Spesies \\
\hline Hesperiidae & Carterocephalus & Carterocephalus palaemon \\
\hline Lycaenidae & Euchrysops & Euchrysops cnejus \\
\hline Nymphalidae & Danaus & Danaus melanippus \\
& Maniola & Maniola jurtina \\
& Neptis & Neptis hylas \\
\hline Papilionidae & Papilio & Papilio lowi \\
\hline Pieridae & Appias & Appias libythea \\
& Catopsilia & Catopsilia pyranthe \\
& Eurema & Eurema hecabe \\
\hline Riodinidae & Abisara & Abisara echerius \\
\hline
\end{tabular}

Dari hasil penelitian yang dilakukan terdapat 10 spesies kupu-kupu dari 6 Famili. Spesies kupu-kupu yang didapatkan yaitu Carterocephalus palaemon dari Famili Hesperiidae, Euchrysops cnejus dari Famili Lycaenidae, Danaus melanippus, Maniola jurtina, dan Neptis hylas dari Famili Nymphalidae, Papilio lowi dari Famili Papilionidae, Appias libythea, Catopsilia pyranthe, dan Eurema hecabe dari Famili Pieridae, dan Abisara echerius dari Famili Riodinidae. Spesies kupu-kupu yang ditemukan paling banyak dari Famili Nymphalidae dan Pieridae dengan masing jumlah spesies 3. Menurut Rahayuningsih et al. (2012), kupu-kupu dari Famili Nymphalidae merupakan kupu-kupu sering ditemukan. Kupu-kupu dari Famili Nymphalidae memiliki sifat terbang kuat, aktif dan cepat (Dalem \& Joni, 2017). Menurut Lestari et al. (2015), kupu-kupu dari Famili Nymphalidae cenderung bersifat polifag (mempunyai jenis makanan lebih dari satu macam), sifat inilah yang memungkinkan Nymphalidae tetap dapat memenuhi kebutuhannya akan tumbuhan inang meskipun tumbuhan inang utamanya tidak tersedia.

Kupu-kupu yang didapat banyak ditemukan pada perbatasan ekosistem perkebunan dan persawahan. Pada perbatasan ekosistem perkebunan dan persawahan merupakan tempat yang banyak ditumbuhi vegetasi bawah yang mendukung habitat kupu-kupu. Menurut Rahayu \& Basukriadi (2012), vegetasi semak dan perdu merupakan vegetasi yang mendukung habitat kupu-kupu. Menurut Septianella et al. (2015), vegetasi ini juga merupakan sumber makanan bagi kupukupu.

Rata-rata suhu udara harian di Desa Serdang Menang, Kecamatan Sirah Pulau Padang, Kabupaten Ogan Komering Ilir sebesar $30,9^{\circ} \mathrm{C}$ dengan rata-rata suhu udara pada pagi hari sebesar $28,9{ }^{\circ} \mathrm{C}$, rata-rata suhu udara pada siang hari sebesar $33,0{ }^{\circ} \mathrm{C}$ dan rata-rata suhu udara pada sore hari sebesar 30,9 ${ }^{\circ} \mathrm{C}$. Suhu udara minimum harian sebesar $23,0{ }^{\circ} \mathrm{C}$ dan suhu udara 
maksimum harian sebesar $39,2{ }^{\circ} \mathrm{C}$. Ratarata intensitas cahaya harian sebesar 19.876,4 lux dengan rata-rata intensitas cahaya pada pagi hari sebesar 3.850,2 lux, rata-rata intensitas cahaya pada siang hari sebesar 31.379,8 lux dan rata-rata intensitas cahaya pada sore hari sebesar 24.399,3 lux. Rata-rata kelembaban udara harian sebesar 68,6 \% dengan rata-rata kelembaban udara pada pagi hari sebesar $81,0 \%$, rata-rata kelembaban udara pada siang hari sebesar $60,6 \%$ dan rata-rata kelembaban udara pada sore hari sebesar $64,3 \%$.

Menurut Amir dan Kahono (2000) dalam Lestari et al. (2015), keberadaan kupu-kupu di suatu habitat sangat erat kaitannya dengan faktor lingkungan baik faktor abiotik seperti intensitas cahaya matahari, temperatur, kelembaban udara dan air, maupun faktor biotik seperti vegetasi dan satwa lain. Hal ini yang menyebabkan Keanekaragaman kupu-kupu di suatu tempat berbeda dengan tempat yang lain.

\section{Kesimpulan}

Berdasarkan penelitian yang telah dilakukan didapatkan kesimpulan yaitu:

a. Spesies kupu-kupu yang terdapat di Desa Serdang Menang, Kecamatan Sirah Pulau Padang, Kabupaten Ogan Komering Ilir paling banyak dari Famili Nymphalidae dan Pieridae.

b. Kupu-kupu yang ditemukan paling banyak terdapat pada perbatasan ekosistem perkebunan dan persawahan.

\section{Daftar Pustaka}

Amir, M \& Kahono, S. 2000. Serangga Taman Nasional Gunung Halimun Jawa Bagian Barat. Jakarta: JICA. Dalam. Lestrasi, D.F., Rizma, D.A.P., Muhammad, R., dan Atika, D.P. 2015. Keanekaragaman kupukupu (Insekta: Lepidoptera) di Wana Wisata Alas Bromo, BKPH Lawu Utara, Karanganyar, Jawa Tengah. PROS SEM NAS MASY BIODIV INDO. 1(6): 1284-1288.
Dalem, A.A.G \& M. Joni. 2017. Jenis-Jenis Kupu-Kupu Yang Ditemukan di Kawasan Pariwisata Ubud, Bali. Prosiding SEMINAR NASIONAL SAINSTEK 2017. 163-177.

Katalog BPS OKI. 2017. Kabupaten Ogan Komering Ilir Dalam Angka 2017. Badan Pusat Statistik Kabupaten Ogan Komering Ilir.

Lestrasi, D.F., Rizma, D.A.P., Muhammad, R., dan Atika, D.P. 2015. Keanekaragaman kupu-kupu (Insekta: Lepidoptera) di Wana Wisata Alas Bromo, BKPH Lawu Utara, Karanganyar, Jawa Tengah. PROS SEM NAS MASY BIODIV INDO. 1(6): 1284-1288.

Rahayuningsih, M., R. Oqtafiana, dan B. Priyono. 2012. Keanekaragaman Jenis Kupu-Kupu Superfamili Papilionoidae di Dukuh Banyuwindu Desa Limbangan Kecamatan Limbangan Kabupaten Kendal. Jurnal MIPA. 35(1): 1120.

Rahayu, S.E. \& A. Basukriadi. 2012. Kelimpahan dan Keanekaragaman Spesies Kupu-Kupu (Lepidoptera; Rhopalocera) Pada Berbagai Tipe Habitat di Hutan Kota Muhammad Sabki Kota Jambi. Biospecies. 5(2): 40-48.

Septianella, G., Djunijanti, P., dan Hidayat, Y.S. 2015. Keanekaragaman kupukupu (Lepidoptera) di kawasan

Desa Pasirlangu, Kecamatan Cisarua, Kabupaten Bandung Barat, Jawa Barat. PROS SEM NAS MASY BIODIV INDON. 1(8): 1816-1820. 